ISSN 0819-2642

ISBN 0734025009

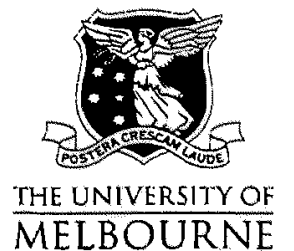

THE UNIVERSITY OF MELBOURNE

DEPARTMENT OF ECONOMICS

RESEARCH PAPER NUMBER 845

APRIL 2002

\title{
RISK PREFERENCE AND EMPLOYMENT CONTRACT TYPE
}

by

Sarah Brown
$\&$
Lisa Farrell
$\&$
Mark N. Harris
$\&$
ohn G. Sessions

Department of Economics

The University of Melbourne

Melbourne Victoria 3010

Australia. 


\title{
Risk Preference and Employment Contract Type
}

\author{
Sarah Brown ${ }^{a}$, Lisa Farrell ${ }^{b}$, Mark N. Harris ${ }^{c}$ and John G. Sessions ${ }^{d}$ \\ ${ }^{a}$ Department of Economics \\ University of Leicester, University Road, Leicester \\ Leicestershire LEI 7RH \\ England \\ ${ }^{b}$ Department of Economics \\ University of Melbourne, Melboume \\ Victoria 3010 \\ Australia \\ ${ }^{b}$ Melbourne Institute \\ University of Melbourne, Melbourne \\ Victoria 3010 \\ Australia \\ $\&$ \\ Central European University \\ Budapest, Hungary \\ ${ }^{d}$ Department of Economics and Finance \\ Brunel University, Uxbridge \\ England
}

\begin{abstract}
We consider three broad types of employment contract vis. self-employment, PRP, and fixed wage employment. We focus on the implied degree of income risk associated with each type of employment contract, arguing that such risk falls as we move from self-employment at one extreme to fixed wage employment at the other. We investigate the possibility that there is a systematic relationship between employment within a particular contract type and risk preference as proxied by expenditure on risky goods and goods associated with risk averse behaviour. A typical question might be: "do self-employed individuals attempt to compensate for the relatively high level of income risk they face by reducing their expenditure on relatively risky goods? Or, do such individuals have a taste for risk which they express in both their working and non-working life?' Our empirical analysis, based on pooled cross-section data drawn from the British Family Expenditure Survey 1997-2000, provides evidence of a systematic relationship between employment contract type and risk preference, with, for example, self-employed workers being more (less) likely to engage in the consumption of "risky" (financial security) products. The results are based the Ordered Generalized Extreme Values model (OGEV), a relatively infrequently used discrete choice model, which importantly allows for ordering and correlation in the observed alternatives.
\end{abstract}

Key Words: Risk Preference; Self-Employment; Performance Related Pay; Ordered Alternatives; OGEV model. JEL Classification: J20, J23, J24

Acknowledgements: We are grateful to the ESRC Data Archive for supplying the Family Expenditure Surveys, 1997 to 2000. We express thanks to Michael Shields for valuable comments. The normal disclaimer applies. 


\section{Introduction}

The nature of the employment contract has long intrigued economists. Particular emphasis has recently focused upon the implications of fixed wage contracts, self-employment and performance related pay (PRP). The efficiency wage hypothesis, for example, has examined the notion that the firm's production costs might be inversely related to the level of pay and, in so doing, has proffered an explanation for equilibrium unemployment (Shapiro and Stiglitz, 1984). On the other hand, the analysis of self-employment has concentrated on its potential as a means of alleviating unemployment (Taylor, 1996). Perhaps most controversial, however, has been the academic and popular interest in PRP. Re-kindled by Weitzman's (1985) purported macroeconomic benefits of profit sharing, attention has turned towards the more readily discernible, and originally lauded, microeconomic benefits of PRP schemes broadly defined (Blinder, 1990). ${ }^{1}$

In this paper we investigate the degree of 'income risk' associated with these three broad types of employment contract. Fixed wage employment, for example, implies relatively stable pay. ${ }^{2}$ In contrast, a self-employed worker can offer increasingly competitive tenders as the demand for his/her labour services declines, thereby maintaining a vestige of employment, albeit at or near his/her reservation wage. For such individuals price is fluid. PRP contracts, comprising an element of both fixed and variable pay, provide a mid point between these two extremes. In what follows, we focus primarily on income risk and so presume that self-employment is relatively more risky than PRP, which is itself relatively more risky than fixed wage employment.

If individuals were identical in terms of their attitudes towards risk, and in the absence of ability and/or capital constraints, one would anticipate a pooling equilibrium with all workers flocking to one of the three contacts. More realistically, a spectrum of risk aversion and the presence of such constraints would imply a separating equilibrium, with the expected utility of

\footnotetext{
${ }^{1}$ We define PRP as those contracts in which an element of total compensation is based on employee performance. This includes both formal (e.g. employee share ownership, profit sharing) and informal schemes (e.g. discretionary bonus).

${ }^{2}$ However, the inability of prices to absorb a productivity or demand shock may result in layoffs.
} 
employment across each of the three contracts types being equalised. An interesting line of enquiry is therefore to ascertain the attitudes towards risk of individuals employed within each contract type. Our hypothesis is that there is a systematic relationship between risk preference/aversion and the observed employment contract. We make no presumption as to the direction of this relationship. A taste for risk may be expressed in terms of both consumption and employment; for example, risk lovers may be both self-employed and spend more time (and money) on risky activities such as gambling. Alternatively, individuals may be more inclined to gamble if they have access to a relatively stable income stream; or because they are self-employed they may be relatively less inclined to gamble. ${ }^{3}$ We have no prior as regards the complementarity or substitutability of employment contract types and consumption risk. Our aim is simply to ascertain whether there is a systematic relationship across the three contracts types.

The novelty of our approach is threefold. Firstly, in contrast to the limited amount of existing research in this area, which focuses solely on self-employment, we set our analysis within a wider framework by focusing on a range of employment contract types which are explored collectively rather than in isolation. Secondly, we utilise a set of proxy variables such as participation in gambling activities and types of insurance held to capture attitudes towards risk. Our data which is drawn from the British Family Expenditure Surveys 1997 to 2000 is particularly appropriate for our purpose since it harbours the key facets required for this analysis, containing detailed information on employment contracts as well as individual and household characteristics. Finally, in our empirical analysis we focus on the Ordered Generalized Extreme Values (OGEV) model. Somewhat surprisingly this model is infrequently used in practice. It is appropriate for our analysis, as it retains the flexibility of the MNL whilst simultaneously allowing for ordering and correlation in the observed outcomes.

\footnotetext{
3 Another aspect here concerns the compensating wage differentials associated with each contract type. If selfemployment is the most risky contract it may imply higher mean income which, if gambling is a normal good, will imply higher gambling expenditures ceteris paribus.
} 
Our modelling strategy is to present results obtained from an Ordered Probit model and also the OGEV model. We order employment contract types according to the implied degree of 'income risk' associated with each contract: fixed wage employment; PRP; self-employment. Given the general consensus that self-employment is inherently more risky than fixed wage employment, our ranking in terms of income risk seems appropriate. The results, derived from analysis of the British Family Expenditure Survey (FES) over the period 1997-2000, do suggest a systematic relationship between our risk preference/aversion proxies and employment under a particular type of contract. To be sure, our results suggest the existence of a positive relationship between risk preferences and employment within a particular type of contract.

The paper is set out as follows: Section II discusses some background issues to our thesis; Section III outlines our data and methodology; Section IV presents the results; and Section V presents some final comments.

\section{Economic Considerations}

Although the nature of the employment contract has long intrigued economists, the relationship between attitudes towards risk and the nature of employment contracts has essentially been ignored. One explanation for this concerns the difficulty of measuring risk empirically. Several studies have relied on self-reported measures. In their analysis of medical group practices, for example, Gaynor and Gertler (1995) analyse self-reported risk preference measures based on the level of importance attached to the regularity of income. Similarly, Shaw (1996), in a study of human capital investment and the degree of relative risk aversion, measures risk via information pertaining to the allocation of wealth to risky assets and survey information regarding individuals' attitudes towards financial risk.

In terms of our three broad classifications of employment contract, research has focused most clearly on the relationship between self-employment and risk. Recent years have heralded a resurgence of interest amongst both academics and policy makers in the determinants of self- 
employment, and its role as a potential solution to unemployment and poverty. ${ }^{4}$ As a result of (or perhaps, as an inspiration to) this interest, the self-employed have emerged as an important class of workers in many developed countries, accounting for sixteen per cent of the workforce in Australia, ten per cent in Canada, nine per cent in the UK and nine per cent in the US in 1999 (Le, 1999). A number of approaches have been developed to explain the supply and demand of self-employment, emphasising to varying degrees sociological, psychological, and economic factors (see Keeble et al., 1993, for a review).

The basic economic argument is that individuals decide whether or not to enter selfemployment on the basis of the relative utilities on offer. Such an approach encapsulates unemployment push and pull factors, with displaced workers being pushed or pulled into selfemployment by supply side considerations. Relative returns, however, are but one part of the story. It has long been recognised that returns to self-employment are intrinsically riskier than the returns to salaried employment. An interesting issue is then the type of individual attracted into selfemployment.

Self-employment has long been regarded as an indicator of 'entrepreneurship' and as a conduit through which the demand for labour can be increased (Blanchflower and Oswald, 1998). Indeed, it has long been argued that the most important factor limiting the size of a firm is the coordinating ability of the entrepreneur leading the firm (Kalldor, 1934) and attitudes towards risk were identified as an important determinant of entrepreneurship by as early as Knight (1921).

One of the most influential contributions to this literature was the seminal paper by Lucas (1978). The thrust of Lucas' model is the observation that within a closed economy, a full employment equilibrium will involve some people becoming entrepreneurs and creating firms that will in turn employ others. The actual division between entrepreneurs and salaried labour depends

\footnotetext{
${ }^{4}$ A number of government policies confirm this interest. In Australia the 'New Enterprise Incentive Scheme' has provided training and income support to the unemployed that wish to enter self-employment. In the UK the government provides transfer payments to the unemployed when they start their business, whilst in the US a number of schemes have emerged to encourage the growth of minority small business, see Le (1999).
} 
crucially on the distribution of individuals' characteristics within the population, in particular entrepreneurial talent that varies across individuals. The Lucas model was extended to explicitly include risk by Kihlstrom and Laffont (1979) and Kanbur (1979). Kihlstrom and Laffont (1979) attempt to explain how individuals make the decision between a risky, but potential high rewarding entrepreneurial career, and a riskless wage:

\begin{abstract}
There are, of course, many factors that should influence this choice. The most important ones would include entrepreneurial ability, labour skills, attitudes towards risk, and initial access to the capital required to create a firm. The present paper focuses on risk aversion as the determinant which explains who becomes an entrepreneur and who becomes a labourer (Kihlstrom and Laffont, 1979, p. 720).
\end{abstract}

Kanbur (1979) develops a model of occupational choice under risk. Individuals can chose to become a wage-earning employee, supplying a single unit of homogenous labour and receiving the riskless competitive wage; or alternatively, they can chose to become an entrepreneur, employing other workers and producing a homogenous output according to a production function that includes the individual's endowment of entrepreneurial ability. Entrepreneurship is risky in the sense that individuals have no prior information as regards their own particular level of ability. In Kanbur's model individuals apply the common population distribution of aptitude whilst perceived expected ability remains constant across individuals. This approach is extended in Van Praag and Cramer (2001) who allow individual expectations of entrepreneurial talent to depend upon specific personal characteristics. The corresponding talent distribution, but not the outcome, is known to the individual. Thus an individual will choose entrepreneurship if the expected rewards from so doing exceed that from the wages offered by employment. These expected rewards will depend on the individual's assessment of his/her own ability and on his/her attitude towards risk. Entrepreneurial success is determined by actual ability and these factors will determine the distribution of a given labour supply over entrepreneurs and employees. Strong empirical support for the model is found from Dutch survey data that suggests that both risk-taking and ability are important determinants of successful entrepreneurship. 
A number of papers have been developed from those outlined above including Calvo and Wellisz (1980), Evans and Jovannvic (1989), Holtz-Eakin et al. (1994a, 1994b), Jovanovic (1994), and Blanchflower and Oswald (1998). Since the 1980s, however, an alternative research program into self-employment and entrepreneurship has emerged which has tended to extend psychological studies focusing on factors such as 'achievement motivation' and 'attitudes towards control' (see Brockhaus, 1980 and the reviews by Wortman, 1987 and Brockhaus and Hortwitz, 1986) whilst the most recent research has focused on the attributes of the self-employed rather than on their propensity to take risk (see, for example, Georgellis and Wall, 2000, Le, 1999 and Clarke and Drinkwater, 2000). ${ }^{5}$

Our focus in this paper is the relationship between an individual's 'taste' for risk and the type of employment contract in which he/she is observed. The novelty of our approach lies in the range of employment contracts considered, the use of a number of proxy variables to capture attitudes towards risk and the estimation techniques employed. In terms of the former we envisage a spectrum of contracts which may be nested in the illustrative form: $w_{j}=\left(1-\lambda_{j}\right) \bar{w}+\lambda_{j} f(e ; \theta)$; where $j=f w$, prp, se (denoting 'fixed wage', 'PRP' and 'self-employment', respectively); $w_{j}$ denotes total remuneration; $\bar{w}$ the component of total remuneration that is independent of worker performance; $f(e ; \theta)$ some function mapping the relationship between worker performance $\theta$ and a stochastic parameter $e$ and; $\lambda_{j}$ the proportion of total remuneration that is dependent upon performance. We presume that $\lambda_{f w}=0, \lambda_{p r p} \in(0,1)$ and $\lambda_{s e}=1$ such that $w_{f w}=\bar{w}$, $w_{p r p}=\left(1-\lambda_{p r p}\right) \bar{w}+\lambda_{p r p} f(e ; \theta)$, and $w_{s e}=f(e ; \theta)$. Assume for simplicity that $\theta$ can take two values, $\theta=\left(\theta_{H}, \theta_{L}\right)$, with $f\left(e ; \theta_{H}\right)>f\left(e ; \theta_{L}\right)$, the range of income to which an individual is

\footnotetext{
${ }^{5}$ One exception is Parker (1996) who analyses the role of risk in the self-employment decision.
} 
exposed is defined by $\Delta w=\lambda_{j}\left[f\left(e, \theta_{H}\right)-f\left(e, \theta_{L}\right)\right]$ with the implication that income risk is increasing in $\lambda_{j}{ }^{6}$

Since risk preferences are unobservable we follow Hersch and Pickton (1995), Hersch and Viscusi (1990) and Barsky et al (1997) in using proxies to capture individual risk preference. Hersch and Viscusi (1990) and Hersch and Pickton (1995) proxy risk preference by individuals' cigarette smoking and seat belt use. These studies explore how differences in individuals' attitudes towards risk affect wage-risk trade-offs. The revealed risk attitudes have an important effect on observed risk premiums with non-smokers receiving a greater wage-risk trade-off than smokers.

Barsky et al. (1997) adopt an experimental approach in order to elicit individual preference parameters. Participants were asked to respond to situations designed to yield information about their risk aversion such as their willingness to gamble lifetime income. Their findings suggest that risk tolerance is positively and significantly related to risky behavior such as smoking, drinking, failing to have insurance and moreover the decision to be self-employed. They find a $U$-shaped relationship between years of schooling and risk tolerance. The youngest and the oldest individuals are found to be more risk tolerant, whilst males are found to be more risk tolerant than females and white respondents are found to be the least risk tolerant. Finally, the self-employed are found to have a higher risk tolerance and have a much lower average propensity to be insured than employees.

Our intention is to analyse the differences in the consumption of various goods associated with risk, across employment contract types. In addition to exploring such consumption, we explore how factors such as education, age, gender, presence of dependent children and marital status affect employment contract type. Such issues have been explored in the theoretical literature on attitudes towards risk. Robson (1996), for example, explores the possibility that males are less risk averse than females from a theoretical perspective. Shaw (1996) suggests that more educated individuals

\footnotetext{
${ }^{6}$ The presumption here is, of course, that employment is secure. As discussed previously, the inability of an
} 
are more likely to be risk-takers and that education and occupational status are related - thus one might predict that participation in consumption on activities which reveal attitudes towards risk and household characteristics that affect individuals preference for risk will be related to contract type.

\section{Data and Methodology}

\section{Data}

Our data is drawn from the Family Expenditure Survey (FES) for the UK, which is a nationally representative survey that has been conducted on an annual basis since 1957. Some 10000 households are selected each year to take part in the $F E S$, and the average response rate is approximately $70 \%$. The main aim of the survey is to provide a reliable source of information on household expenditure, income and other aspects of household finances. To account for seasonal differences in expenditure, face-to-face interviews are spread evenly over the year. Each individual aged 16 or over in the households visited is asked to keep diary records of daily expenditure for two weeks. Respondents are also asked to complete an income questionnaire. This data is especially appropriate for our purposes since it harbours the key facets required for our analysis. It contains detailed information on employment contracts, individual specific characteristics and household specific characteristics.

We use data from the 1997-1998, 1998-1999 and 1999-2000 surveys. Prior to this period the dataset had a slightly different structure and some of the variables required for our analysis are not available. Our sub-sample comprises working adults aged between 18 and 65 who are either self-employed or employed under a fixed wage contract or a contract characterised by a bonus scheme thereby introducing an element of PRP. ${ }^{7}$ The bonus schemes include: Christmas bonuses, productivity bonuses, profit related bonuses, loyalty bonuses, dividends, incentive schemes and performance/sales bonuses. Clearly the nature of these bonuses is somewhat diverse and as such

excessively rigid wage to absorb a productivity or demand shock may result in widespread layoffs. 
may create different incentive mechanisms in the workplace. Sample statistics are set out in Tables 1-3.

Table 1: Distribution of the Sample by Employment Contract

\begin{tabular}{cccccccc}
\hline \multicolumn{2}{c}{ Self-Employed } & \multicolumn{2}{c}{ PRP } & Fixed Wage & \multicolumn{2}{c}{ Total } \\
\hline 1287 & $9.41 \%$ & 3623 & $26.49 \%$ & 8765 & $64.10 \%$ & 13675 & $100.0 \%$
\end{tabular}

It is apparent from Table 1 that fixed wage contracts are the dominant form of employment contract and self-employment is the least common contract type. Table 2 shows there are interesting differences in the incidence of employment contract type given individual characteristics. For example, men are relatively more likely to hold employment contracts associated with income risk. The incidence of self-employment is higher amongst married relative to single, separated, divorced and widowed, respondents. This may reflect a form of risk pooling with married people being attracted to self-employment because they can offset some income risk with other household members (for a full discussion of these issues see Brown et al, 2001). With respect to ethnicity, PRP contracts are more heavily concentrated among whites. Whilst the incidence of self-employment is low amongst blacks, the incidence of self-employment is relatively high among Asians and the 'other' ethnic origin group (which is dominated by the Chinese), tying in with the findings of Borooah and Hart (1999).

One might also hypothesise that both the number and the age of any children will affect a parent's willingness to take on income risk. We therefore look at the number of pre-school and school-age children in the household and find that whilst the former are distributed relatively evenly across employment contracts, the latter are highest amongst self-employed workers. This may reflect the fact that self-employed workers are on average older than workers on PRP or fixed wage contracts.

\footnotetext{
7 A small number of individuals with more than one job, individuals employed by the armed forces and agricultural workers were excluded from the analysis.
} 


\begin{tabular}{|c|c|c|c|}
\hline & Self-Employed & $P R P$ & Fixed Wage \\
\hline \multicolumn{4}{|l|}{$\operatorname{Sex}$} \\
\hline Males & 11.77 & 28.19 & 60.04 \\
\hline Females & 4.67 & 23.07 & 72.26 \\
\hline \multicolumn{4}{|l|}{ Family status } \\
\hline Single & 4.15 & 26.18 & 69.67 \\
\hline Married/Co-habit & 10.28 & 26.79 & 62.39 \\
\hline Separated/Widowed/Divorced & 9.44 & 24.50 & 66.06 \\
\hline Pre-School Children* & 0.22 & 0.23 & 0.18 \\
\hline School-Age Children* & 0.75 & 0.47 & 0.52 \\
\hline \multicolumn{4}{|l|}{ Ethnicity } \\
\hline White & 9.28 & 26.78 & 63.94 \\
\hline Black & 6.04 & 19.23 & 74.73 \\
\hline Asian & 17.54 & 18.66 & 63.81 \\
\hline Other & 10.45 & 23.88 & 65.67 \\
\hline \multicolumn{4}{|l|}{ Age } \\
\hline $17<\mathrm{Age}<19$ & 1.74 & 15.12 & 83.14 \\
\hline $20<$ Age $<29$ & 3.55 & 28.70 & 67.75 \\
\hline $30<$ Age $<39$ & 8.84 & 29.98 & 61.18 \\
\hline $40<$ Age $<49$ & 11.92 & 24.34 & 63.74 \\
\hline Age $>50$ & 14.17 & 23.39 & 63.44 \\
\hline \multicolumn{4}{|l|}{ Education level } \\
\hline Less than GCSE & 14.06 & 22.36 & 63.58 \\
\hline GCSE & 9.29 & 26.94 & 63.77 \\
\hline Further Education & 7.38 & 28.48 & 64.14 \\
\hline Higher Education & 7.78 & 27.28 & 64.94 \\
\hline \multicolumn{4}{|l|}{ Housing Tenure } \\
\hline Rented local authority & 6.11 & 22.17 & 71.72 \\
\hline Rented private & 9.82 & 22.16 & 68.02 \\
\hline Mortgaged & 9.02 & 28.44 & 62.54 \\
\hline Owned & 13.89 & 22.20 & 68.92 \\
\hline \multicolumn{4}{|l|}{ Occupation } \\
\hline Professional & 12.36 & 29.33 & 58.30 \\
\hline Managerial \& technical & 6.99 & 29.78 & 68.23 \\
\hline Skilled & 11.35 & 24.14 & 64.51 \\
\hline Partly skilled & 7.32 & 24.33 & 68.35 \\
\hline Unskilled & 12.78 & 18.85 & 68.37 \\
\hline \multicolumn{4}{|c|}{$\begin{array}{l}\text { Note: Numbers are expressed as a percentage of the total number of individuals across the three } \\
\text { contract types for each individual characteristic except those denoted by }{ }^{*} \text { which represent the } \\
\text { average for each contract type. }\end{array}$} \\
\hline
\end{tabular}

The age profile of people employed on PRP contracts is $n$-shaped. This may be due to that fact that such contracts have been more widely introduced over the last decade and, as such, may be reflecting a cohort rather than an age effect. The age profile of people on fixed wage contracts is skewed towards the youngest age group (i.e. those less than twenty), suggesting that the income uncertainty associated with PRP contracts and self-employment may be prohibitively high for individuals with little labour market experience. In addition, they are less likely to have acquired 
the necessary capital to start a business. The proportion of individuals in self-employment increases with age, a finding that is consistent with the hypothesis that older, displaced workers might turn to self-employment given their relatively low probability of re-employment. It might also reflect the ability of older workers to acquire the necessary start-up capital for, and to better absorb the income uncertainty associated with, self-employment, on account of their longer accumulation of wealth. ${ }^{8}$

Individuals in self-employment have relatively few formal qualifications. PRP contracts, on the other hand, are concentrated amongst people with formal school qualifications and above, whilst individuals holding fixed wage contracts are relatively evenly spread across all levels of schooling. It would appear that whilst educational attainment plays an important role in explaining the probability of holding PRP contacts or being self-employed, it may not be so important in explaining why individuals hold fixed wage contracts. ${ }^{9}$

In relation to housing tenure, fixed wage employees are most likely to be found living in local authority housing, whilst the self-employed are more likely to own their homes outright and PRP workers, are most likely live in homes that are mortgaged. This may reflect the fact that housing equity is often used as collateral to secure loans necessary to start up a small business.

With respect to the occupational class variables, we find that the incidence of fixed wage employment increases as the level of skill associated with the job falls, being particularly concentrated in the partly skilled and unskilled categories. PRP contracts are most common among professionals and managers whilst the incidence of self-employment is high for professional, skilled and unskilled workers.

The focus of our analysis is the link between an individual's observed employment contract type and their taste for risk. Whilst an individual's preference for, or aversion to, risk is not directly observable, our data provides a number of variables that might be considered reasonable proxy

\footnotetext{
${ }^{8}$ See Blanchflower and Oswald (1998) for a detailed analysis of the importance of capital constraints for the probability of becoming self-employed.

This is a further justification of the OGEV model versus the Ordered Probit one (see below) as the former allows coefficients and significance levels to vary across alternatives.
} 
measures. It may be the case that risk-preferring individuals are more likely to consume 'risky' goods such as alcohol, cigarettes and 'gambling', ${ }^{10}$ whilst risk averse individuals are more likely to concentrate resources on financial security through investments yielding unearned income and to purchase insurance products.

Table 3: Mean Expenditure ( $\mathrm{ppw}$ ) and \% of Individuals who engage in risky / risk averse activities

\begin{tabular}{lrrrrrr}
\hline \hline & \multicolumn{1}{c}{ Self-Employed } & \multicolumn{2}{c}{ PRP } & \multicolumn{2}{c}{ Fixed Wage } \\
& Expenditure & $\%$ & Expenditure & $\%$ & Expenditure & $\%$ \\
\hline Home Contents Ins. & - & 66.43 & - & 62.43 & - & 50.92 \\
Life Insurance & 5.84 & 43.82 & 3.32 & 38.01 & 3.18 & 34.54 \\
Alcohol & 11.55 & 69.70 & 12.82 & 75.32 & 10.72 & 71.52 \\
Cigarettes & 4.36 & 28.83 & 3.39 & 25.03 & 3.72 & 27.04 \\
Gambling & 4.76 & 47.48 & 4.45 & 53.11 & 4.23 & 50.43
\end{tabular}

Mean Unearned income (£pw) and \% of Individuals who receive unearned income

$\begin{array}{lllllll}\text { Unearned income } & 27.25 & 66.90 & 14.76 & 72.62 & 15.42 & 63.75\end{array}$

Table 3 sets out, by employment contract type, the mean levels of expenditures on a selection of goods that are thought to reveal information about risk preference/aversion and the mean level of unearned income received (given that unearned income may act as a buffer against employment income risk). It is apparent that the proportion of individuals holding home contents insurance is largest (smallest) for the self-employed (fixed wage workers) and expenditure on life insurance exhibits the same pattern. This is true for the level of expenditure and the percentage of individuals within the contract types who participate in these expenditures. Alcohol expenditure is highest, in value and the level of participation, for PRP workers, whilst cigarette expenditure is largest for self-employed workers. Table 3 also reports the mean levels of unearned income and shows that the self-employed have the highest levels of unearned income whilst the highest proportion of workers within a contract group receiving unearned income are the PRP workers.

\footnotetext{
${ }^{10}$ Gambling expenditure comprises expenditure on football pools, bingo, bookmakers and the national lottery, which represent the key components of gambling expenditure within the UK.
} 


\section{Methodology}

Our econometric methodology is based on pooled cross-section econometric analysis of the relationship between contract type, individual, household and job-specific characteristics, and an extensive set of variables associated with risk preference/aversion. The focus is on discrete choice methods, as the dependent variable is categorical in nature, taking the value of 1 if the individual is employed on a fixed wage contract, 2 if he/she is employed on a PRP contract and 3 if he/she is self-employed.

As is common in the literature (see, for example, Fry et al., 1993), the random utility maximization (RUM) model provides a convenient starting point, with an indirect utility function given by:

$$
U_{i j}=V_{i j}+\varepsilon_{i j}=x_{i j}^{\prime} \beta_{j}+\varepsilon_{i j}
$$

with $i=1, \ldots, N$ and $j=1, \ldots, J . U_{i j}$ is the utility individual $i$ obtains from alternative $j$, which is assumed to be a linear (in parameters) function of their $(k \times 1)$ vector of observed personal heterogeneity, $x_{i j}$ with unknown weights $\beta_{j}$ (that is, the weights are allowed to vary across alternatives). $\varepsilon_{i j}$ is a random disturbance term.

The utilities of equation (1) are not directly observed, what is observed is the realisation of this latent variable, with $Y_{i j}=j$ if the $i^{\text {th }}$ individual is employed under an employment contract of type $j$. It is assumed that the individual is characterised by that alternative which maximizes his/her utility from the full set of alternatives $C, C=\{1, \ldots, J\}$.

Under the usual assumption that $\varepsilon_{i j}$ follows an Independent Type 1 Extreme Value distribution the usual MNL results (see Maddala, 1989), where the associated probabilities are:

$$
P_{i j}=\frac{\exp \left(V_{i j}\right)}{\sum_{k=1}^{J} \exp \left(V_{i k}\right)} .
$$


MNL models are extremely popular in practice due to their simplicity, flexibility and ease of estimation. However, they do impose some very strong restrictions on the model, most notably the Independence of Irrelevant Alternatives (IIA). This property states that the odds ratio $P_{i j} / P_{i k}, j \neq k$, is independent of all other alternatives in the choice set, and moreover independent of additions to, and deletions from, the full set of alternatives. It appears infeasible that the probability of selfemployment to PRP will be independent of the presence of fixed wage employment, for example. This problem is exacerbated by the fact that tests for IIA generally have very poor performance (see, for example, Fry and Harris, 1996). Moreover, importantly here, we need to allow for ordering in the dependent variable. That is, the approach advocated in this paper is that employment contract types are necessarily ordered by the degree of income risk. PRP contracts, comprising an element of both fixed and variable pay, offer a mid point between the two extremes of fixed wage and self-employment. We focus primarily on the risk of income and so presume that self-employment is relatively more risky than PRP employment, which is itself relatively more risky than fixed wage employment. Our raw data supports this hypothesis with the standard deviation of earnings around the mean being 200.72 for fixed wage employment, 371.43 for PRP employment and 828.75 for self-employment. ${ }^{11}$

An obvious approach to take such ordering into account would be to assume that $\beta_{j}=\beta, \forall j$ and also that the $\varepsilon_{i j}$ follow a standard normal distribution. Inclusion of the so-called cut-off points yields the Ordered Probit model (Maddala, 1989), with the following associated probabilities:

$$
P\left(Y_{i}=1\right)=\Phi\left(\mu_{1}-\beta^{\prime} X_{i}\right)
$$

\footnotetext{
${ }^{11}$ Our hypothesis that PRP generates a relatively risky stream of income accords with the results of Seiler (1984) who finds that 'incentive' workers in the US manufacturing sector experience higher yet more dispersed earnings than 'time rate' workers. Similarly. Rees and Shah (1986) find that the variance of earnings for the self-employed is over three times that of paid employees.
} 


$$
\begin{aligned}
& P\left(Y_{i}=2\right)=\Phi\left(\mu_{2}-\beta^{\prime} X_{i}\right)-\Phi\left(\mu_{1}-\beta X_{i}\right) \\
& P\left(Y_{i}=3\right)=1-P\left(Y_{i}=1\right)-P\left(Y_{i}=2\right)
\end{aligned}
$$

where $\Phi($.$) denotes the cumulative standard normal distribution and the \mu$ 's are cut-off points (or boundary parameters). Significance of these boundary parameters is often regarded as a test of the presence of ordering in the data. The data rarely rejects this hypothesis, even if there does not appear to be a strong case for ordering in the data. Moreover, the Ordered Probit is relatively inflexible, as the coefficient vector $\beta$ is restricted to be equivalent across alternatives. Indeed as Small (1987) states,

\begin{abstract}
'The ordered response model arises when the observed responses reflect intervals of a latent variable that is linear in unknown parameters, and it specifies an ogive function for the sum of the first (or last) $\mathrm{k}$ choice probabilities; it is sometimes called "ordered logit" or "ordered probit" if the ogive function is logistic or normal. The need to specify a single latent variable as a linear function causes ordered response models to lack the flexibility of MNL or multivariate probit' (Small, 1987, p.410). ${ }^{12}$
\end{abstract}

A more attractive alternative appears to be Small's Ordered Generalised Extreme Value (OGEV) model (Small, 1987 and 1994). The OGEV model expands on the MNL one by allowing for ordering in the data and correlations of alternatives in close vicinity. It nests the MNL model and moreover provides a simple test for such (and thus explicitly for ordering as well). This model is particularly well suited to this application, as correlations between different employment contracts appear very likely a priori.

It is possible to allow the window of correlation to be arbitrarily large. However, this increases the number of parameters to be estimated and makes estimation cumbersome (Small, 1987). Therefore we restrict attention to the standard OGEV model (Small, 1987, p.414). Moreover with only three outcomes, this additional complication does not appear to be warranted. The

\footnotetext{
${ }^{12}$ In the context of our application the flexibility of our statistical model to allow the coefficients and significance levels to vary across alternatives is especially important given that we know that individual characteristics vary across contract types, for example the self-employed tend to be older than individuals in other types of employment.
} 
standard OGEV implies a correlation between neighbouring alternatives only. This correlation declines the further away the two outcomes $j$ and $k$ are, and is zero when $|j-k|>2$. Although the correlations cannot be explicitly written in closed form, they are inversely related to $\rho$ (defined below). The standard OGEV probabilities are given by:

$$
\begin{aligned}
P_{i j}^{O G E V}= & \frac{\exp \left(\rho^{-1} V_{i j}\right)}{\sum_{r=1}^{J+1}\left[\exp \left(\rho^{-1} V_{i, r-1}\right)+\exp \left(\rho^{-1} V_{i r}\right)^{\rho}\right]} \times \\
& {\left[\left(\exp \left(\rho^{-1} V_{i, j-1}\right)+\exp \left(\rho^{-1} V_{i j}\right)\right)^{\rho-1}+\left(\exp \left(\rho^{-1} V_{i j}\right)+\exp \left(\rho^{-1} V_{i, j+1}\right)\right)^{\rho-1}\right] }
\end{aligned}
$$

with the convention that $\rho^{-1} V_{i 0}=\rho^{-1} V_{i, l+1}=0$. For obvious reasons, there is a restriction that $0<\rho \leq 1$. As $\rho \rightarrow 1$ OGEV probabilities converge to MNL ones, which give a simple parameter restriction $(\rho=1)$ based test of the OGEV versus MNL formulations. This test is also one of ordering versus non-ordering of the outcomes. As $\rho \rightarrow 0$, the associated cumulative distribution function is a degenerate one, but one still consistent with random utility maximization (Small, 1987).

Defining an indicator as

$$
d_{i j}=\left\{\begin{array}{l}
1 \text { if individual } i \text { chooses alternative } j \\
0 \text { otherwise }
\end{array}\right.
$$

the parameters of equation (6) can be estimated by maximizing the log-likelihood function

$$
\ell(\beta, \rho \mid X)=\sum_{j=1}^{J} \sum_{i=1}^{N} d_{i j} \ln \left(P_{i j}^{O G E V}\right) .
$$

As with the MNL model, for identification purposes, the $\beta$ vector for one of the alternatives (here $\beta_{1}$ ) is normalised to zero, and the remaining choice coefficient vectors are interpreted relative to this omitted one. 
The vector of explanatory variables, $x_{i}$, contains individual attributes and household characteristics thought to influence an individual's type of employment contract. The individual characteristics include gender, age, ethnic origin, family status and level of education. In addition, we control for job specific characteristics such as occupation and industry. We also control for the number of pre-school children in the household, the number of school age children, housing tenure and geographical region. The inclusion of the risk proxy variables in the model is less straightforward. Whilst they are a key focus of this paper it is not possible to simply include the variables in Table 3 directly into the model. Given that they are jointly acting as a proxy for the unobserved risk preference of the individual, it is likely that they will be highly correlated with each other. We therefore adopt a principal component factor analysis approach (Spearman, 1904). Thus we find a small number of common factors (say $q$ of them) that linearly construct the $p$ original variables such that:

$$
y_{i j}=z_{i 1} b_{1 j}+z_{i 2} b_{2 j}+\ldots+z_{i q} b_{q j}+e_{i j}
$$

where $y_{i j}$ is the value of the $i$ th observation of the $j$ th variable (say alcohol expenditure), $z_{i k}$ is the ith observation on the $k$ th common factor, $b_{k j}$ is the set of linear coefficients called the factor loadings, finally, $e_{i j}$ is similar to the residual in a regression equation but is known as the $j$ th variable's unique factor. That is, we identify underlying factors that contain most of the information in our 6 risk preference proxy variables. As is standard practice we retain only those factors that have eigenvalues $>0$. These remaining factors can then be included as orthogonal covariates in the regression analysis. Once the factors and their loadings have been estimated they can be allocated an interpretation. Interpretation usually implies examining the $b_{k j}$ 's in order to name the factors - this may be a fairly subjective process. In our case the risk proxy variables can be summarised by two factors which following rotation intuitively reflect the original risk proxy variables, where rotation re-expresses the factors so that the loadings on a few initial variables are 
as large as possible. The first factor 'financial security', loads most heavily on contents insurance $^{13}$, life insurance and unearned income variables and the second factor 'risk' in the regression analysis below is most heavily loaded on our original smoking, drinking and gambling expenditure variables. The fact that most of our risk proxies are measured in terms of levels of expenditure does give rise to one further issue. Different employment contracts could be associated with different levels of income and thus changes in the level of expenditure may simply represent an income effect rather than an attitude towards risk. The inclusion of income as an explanatory variable or as a scaling parameter for the levels of expenditure is not possible here as it is an endogenous variable. However observation of the correlation between income and the risk proxies suggests that this problem does not arise. The correlation coefficients are small (the largest being 0.23 for income and life insurance).

\section{Results}

The results are set out in Tables 4 and 5 below. For comparison purposes, the Ordered Probit results are presented first followed by our preferred model, the OGEV.

\footnotetext{
${ }^{13}$ This variable is a binary variable indicating if the individual has home contents insurance, whilst our other risk proxy variables are measured in levels of expenditure. For a principal component factor analysis this is not a problem as the aim is to find the factors that account for the key variations in the original variables.
} 
Table 4: Ordered Probit Analysis

$1=$ Fixed Wage; $2=$ PRP Contract; $3=-$ Self-Employed

\begin{tabular}{|c|c|c|}
\hline Variable & Coef. & $t-$ stat \\
\hline \multicolumn{3}{|l|}{ Demography } \\
\hline Black & -0.149 & -1.410 \\
\hline Asian & 0.076 & 0.960 \\
\hline Other Ethnic & -0.056 & -0.500 \\
\hline Age/10 & 0.091 & 6.880 \\
\hline Age-Squared/100 & -0.081 & -2.940 \\
\hline Female & -0.007 & -0.160 \\
\hline Separated/Widowed/Divorced & -0.135 & -4.020 \\
\hline Single & 0.079 & 3.410 \\
\hline Number Pre-School Children & 0.047 & 3.640 \\
\hline Number School Children & 0.091 & 6.880 \\
\hline \multicolumn{3}{|l|}{ Region } \\
\hline Yorkshire And Humberside & 0.133 & 2.010 \\
\hline North West & 0.126 & 1.970 \\
\hline East Midlands & 0.120 & 1.780 \\
\hline West Midlands & 0.129 & 1.970 \\
\hline East Anglia & 0.100 & 1.290 \\
\hline Greater London & 0.220 & 3.400 \\
\hline South East & 0.208 & 3.510 \\
\hline South West & 0.202 & 3.080 \\
\hline Wales & -0.010 & -0.130 \\
\hline Scotland & -0.029 & -0.430 \\
\hline Northern Ireland & -0.095 & -1.280 \\
\hline \multicolumn{3}{|l|}{ Education } \\
\hline GCSE & 0.049 & 1.470 \\
\hline Further Education & 0.066 & 1.720 \\
\hline Higher Education & 0.101 & 2.440 \\
\hline \multicolumn{3}{|l|}{ Housing Tenure } \\
\hline Private Rent & 0.198 & 3.680 \\
\hline Mortgage & 0.209 & 5.170 \\
\hline Owned Outright & 0.255 & 5.090 \\
\hline \multicolumn{3}{|l|}{ Year of Survey } \\
\hline Survey - 1998/99 & 0.057 & 2.140 \\
\hline Survey - $1997 / 98$ & 0.172 & 6.460 \\
\hline \multicolumn{3}{|l|}{ Occupation } \\
\hline Managerial And Technical & -0.136 & -3.170 \\
\hline Skilled & -0.152 & -3.370 \\
\hline Semi-Skilled & -0.159 & -2.960 \\
\hline Unskilled & -0.248 & -2.940 \\
\hline \multicolumn{3}{|l|}{ Risk preference factors } \\
\hline Financial Security & -0.066 & -5.450 \\
\hline Risk & 0.028 & 2.690 \\
\hline \multicolumn{3}{|l|}{ Industry control variables } \\
\hline Cut-off point 1 & 1.001 & 7.36 \\
\hline Cut-off point 2 & 2.068 & 15.09 \\
\hline Log Likelihood (Re & \multicolumn{2}{|c|}{-10637} \\
\hline Number of Observations & \multicolumn{2}{|c|}{13675} \\
\hline
\end{tabular}


Table 8: OGEV Analysis

Reference Category: Fixed Wage Contracts

\begin{tabular}{|c|c|c|c|c|}
\hline \multirow[b]{2}{*}{ Variable } & \multicolumn{2}{|c|}{ PRP Contract } & \multicolumn{2}{|c|}{ Self-Employed } \\
\hline & Coefficient & $t-s t a t$ & Coefficient & $t$ - stat \\
\hline \multicolumn{5}{|l|}{ Demography } \\
\hline Black & -0.194 & 1.108 & -0.119 & 0.389 \\
\hline Asian & -0.350 & 2.263 & 0.559 & 2.989 \\
\hline Other Ethnic & -0.117 & 0.626 & 0.134 & 0.473 \\
\hline Age/10 & 0.787 & 4.958 & 1.517 & 6.059 \\
\hline Age-Squared/100 & -0.100 & 4.894 & -0.135 & 4.739 \\
\hline Males & 0.023 & 0.517 & 0.424 & 4.877 \\
\hline Separated/Widowed/Divorced & 0.099 & 1.840 & 0.362 & 3.202 \\
\hline Single & 0.132 & 1.578 & 0.328 & 2.192 \\
\hline Number Pre-School Children & 0.045 & 1.180 & 0.211 & 3.327 \\
\hline Number School Children & -0.088 & 3.107 & 0.165 & 4.491 \\
\hline \multicolumn{5}{|l|}{ Region } \\
\hline Yorkshire And Humberside & -0.233 & 1.974 & -0.002 & 0.009 \\
\hline North West & 0.130 & 1.611 & 0.021 & 0.158 \\
\hline East Midlands & -0.206 & 1.730 & -0.160 & 0.842 \\
\hline West Midlands & -0.102 & 1.280 & 0.013 & 0.099 \\
\hline East Anglia & 0.178 & 2.020 & -0.084 & 0.547 \\
\hline Greater London & 0.081 & 1.172 & -0.183 & 1.448 \\
\hline South East & -0.045 & 0.486 & -0.201 & 1.178 \\
\hline South West & -0.002 & 0.023 & 0.200 & 1.491 \\
\hline Wales & -0.123 & 1.287 & 0.034 & 0.228 \\
\hline Scotland & -0.047 & 0.406 & 0.085 & 0.463 \\
\hline Northern Ireland & 0.107 & 1.000 & 0.154 & 0.887 \\
\hline \multicolumn{5}{|l|}{ Education } \\
\hline GCSE & 0.079 & 1.402 & 0.081 & 0.968 \\
\hline Further Education & 0.151 & 2.300 & 0.098 & 0.978 \\
\hline Higher Education & 0.185 & 2.662 & 0.173 & 1.605 \\
\hline \multicolumn{5}{|l|}{ Housing Tenure } \\
\hline Private Rent & -0.032 & 0.360 & 0.950 & 5.771 \\
\hline Mortgage & 0.204 & 3.058 & 0.559 & 4.564 \\
\hline Owned Outright & 0.128 & 1.561 & 0.838 & 5.654 \\
\hline \multicolumn{5}{|l|}{ Year Of Survey } \\
\hline Survey - 1998/99 & -0.193 & 4.229 & -0.483 & 6.416 \\
\hline Survey - $1997 / 98$ & -0.134 & 3.002 & -0.341 & 4.684 \\
\hline \multicolumn{5}{|l|}{ Occupation } \\
\hline Managerial And Technical & -0.015 & 0.217 & -0.416 & 3.644 \\
\hline Skilled & -0.341 & 4.017 & -0.078 & 0.658 \\
\hline Semi-Skilled & -0.248 & 2.698 & -0.202 & 1.387 \\
\hline Unskilled & -0.444 & 2.912 & -0.196 & 0.955 \\
\hline \multicolumn{5}{|l|}{ Risk preference factors } \\
\hline Financial Security & -0.084 & 3.770 & -0.132 & 4.806 \\
\hline Risk & 0.033 & 1.918 & 0.042 & 1.668 \\
\hline Industry control variables & yes & & yes & \\
\hline Constant & -1.767 & 5.189 & -7.644 & 9.621 \\
\hline$\rho$ & & 0.609 & stat 4.218 & \\
\hline Log Likelihood (Restricted) & & & 870 & \\
\hline Number of Observations & & & 675 & \\
\hline
\end{tabular}


Prior to discussing the estimated coefficients on the explanatory variables we will present a comparison of our two models. A useful tool in helping to differentiate between the estimation techniques is to ascertain the model's within-sample prediction accuracy. A common measure of predictive accuracy in discrete choice models is the "hit-miss" table. The predictions underlying hit-miss tables are given by assigning individuals the outcome associated with their highest predicted probability across the alternatives and then comparing this to the observed outcome. The hit-miss tables for the two models have been calculated (and for comparison purposes the case of a random assignment of individuals into employment contract types according to sample proportions) and presented in Table 9, which gives a summary of actual versus predicted values.

Table 9: Hit and Miss Tables

\begin{tabular}{|c|c|c|c|c|}
\hline \multicolumn{5}{|c|}{ Ordered Probit } \\
\hline & \multicolumn{4}{|c|}{ Predicted } \\
\hline Actual & Fixed Wage & $P R P$ & Self-Employed & Total \\
\hline Fixed Wage & 8408 & 351 & 6 & 8765 \\
\hline$P R P$ & 3318 & 302 & 3 & 3623 \\
\hline Self-Employed & 972 & 311 & 4 & 1287 \\
\hline Total & 12698 & 964 & 13 & 13675 \\
\hline \multicolumn{5}{|c|}{$O G E V$} \\
\hline \multicolumn{5}{|c|}{ Predicted } \\
\hline Actual & Fixed Wage & $P R P$ & Self-Employed & Total \\
\hline Fixed Wage & 8163 & 487 & 115 & 8765 \\
\hline$P R P$ & 2815 & 757 & 51 & 3623 \\
\hline Self-Employed & 1054 & 58 & 175 & 1287 \\
\hline Total & 12032 & 1302 & 341 & 13675 \\
\hline \multicolumn{5}{|c|}{ Random Assignment } \\
\hline & \multicolumn{4}{|c|}{ Predicted } \\
\hline Actual & Fixed Wage & $P R P$ & Self-Employed & Total \\
\hline Fixed Wage & 5618 & 2322 & 825 & 8765 \\
\hline$P R P$ & 2322 & 960 & 341 & 3623 \\
\hline Self-Employed & 825 & 341 & 121 & 1287 \\
\hline Total & 6443 & 3623 & 1287 & 13675 \\
\hline
\end{tabular}

It is clear that in terms of predictive power the OGEV model is superior, predicting $66.5 \%$ of observations correctly; compared to $63.3 \%$ for the Ordered Probit specification and $49 \%$ in the case of a random assignment of individuals into employment contract types. Figure 1 further illustrates the predictive power of the OGEV model by graphing the actual sample proportions by contract type against those predicted at the sample means by the OGEV model. Whilst the OGEV 
model clearly performs well, it does slightly over predict the number of fixed wage employees and slightly under predict the number of PRP and self-employed workers.

Figure 1: Sample proportions and predictions at sample means

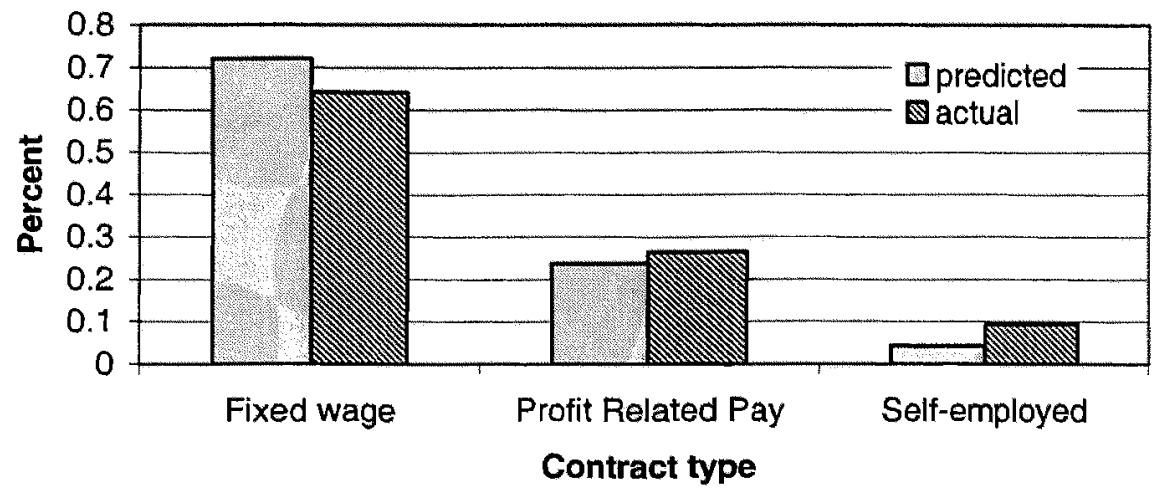

The significance of the cut-off points in the Ordered Probit analysis is often regarded as a test of the significance of ordering in the dependent variable. In our case the significance of the cutoff points in the Ordered Probit model suggests the presence of ordering, however, whilst this model can accommodate the ordering it still has the drawback that it does not allow the coefficients and significance levels to vary across alternatives. This flexibility is especially important in this investigation given that we know from previous literature that individual characteristics do vary across contract types, for example the self-employed tend to be older than individuals employed under other types of contract. In the OGEV specification we can test for the presence of ordering in the following way, as $\rho \rightarrow \infty$ OGEV probabilities converge to MNL ones, which gives a simple parameter restriction ( $\rho=1$ ) based test of the OGEV versus MNL specifications. This is implicitly a test of ordering versus non-ordering of the outcomes in the choice set. It should also be noted that as $\rho \rightarrow 0$ the associated cumulative distribution function is degenerate, but is still consistent with random utility maximisation. Here the statistical significance of $\rho$ in the OGEV specification 
( $\rho=0.609, t$-stat $=-4.218$ ) shows that accounting for the ordering of employment contracts according to their degree of income risk is important in modelling types of employment contract. That is, $\rho$ is statistically significantly different from 0 or 1 (at the $95 \%$ level) and therefore the one tailed test of $\rho>1$ against $\rho=1$ accepts the null hypothesis. Thus ignoring the ordering in our data by applying a standard MNL model would result in misspecification and erroneous inferences. Whilst applying an Ordered Probit model does account for the ordering, we know it is too restrictive given that it does not allow the coefficients and significance levels to vary across alternatives. Thus the OGEV model is our preferred specification.

Before considering the key results of this paper regarding the relationship between employment contract type and risk preference we will briefly discuss the relationship between a number of individual characteristics and employment contract type. Given the greater performance of the OGEV model relative to the Ordered Probit we will concentrate our discussion of the coefficients on the explanatory variables to those estimated from the OGEV model. Moreover, discussion of the OGEV estimates are more informative given that they are not restricted to be the same across all contract types. We begin by discussing the influence of personal characteristics and then proceed to consider household specific characteristics. Due to the complexity of the implicit marginal effects of the OGEV model, which in non-linear models are data dependant and for reasons of clarity we present implied probabilities for different realisation of our explanatory variables. It is apparent from Table 8 that Asian respondents are significantly less likely to be employed on a PRP contract and more likely to be self-employed, than on a fixed wage contract ceteris paribus. This is clearly illustrated in Figure 2, which graphs the predicted probabilities of being in each contract type for each ethnic group where all other explanatory variables have been set at their sample means. The higher incidence of Asians in self-employment is clearly visible. 
Figure 2: Predicted probabilites- Ethnicity

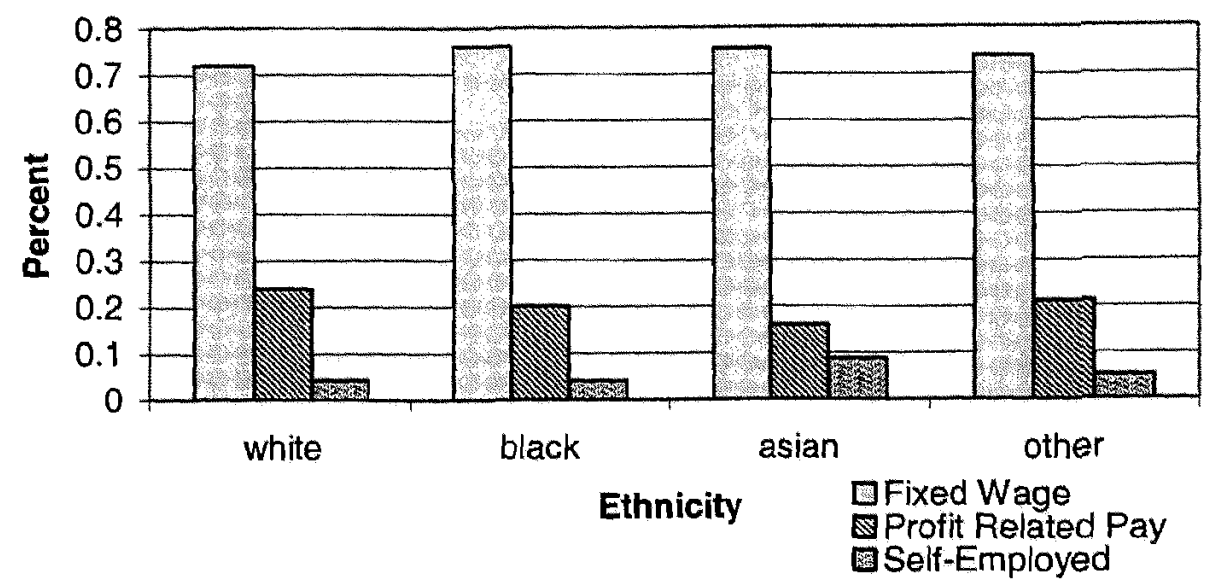

It is also evident from the OGEV results that age significantly impacts on the probability of being in each type of employment contract. The predicted probabilities are graphed in Figure 3 . The age profile of fixed wage employees is u-shaped, whereas the age profile of PRP workers is nshaped. The probability of being in self-employment increases with age in accordance with those of Rees and Shah (1986). The magnitude of the estimated coefficients on the age variable suggest that the self-employed are, on average, older than PRP employees, who are in tum older than fixed wage employees.

Figure 3: Predicted Probabilty- Age

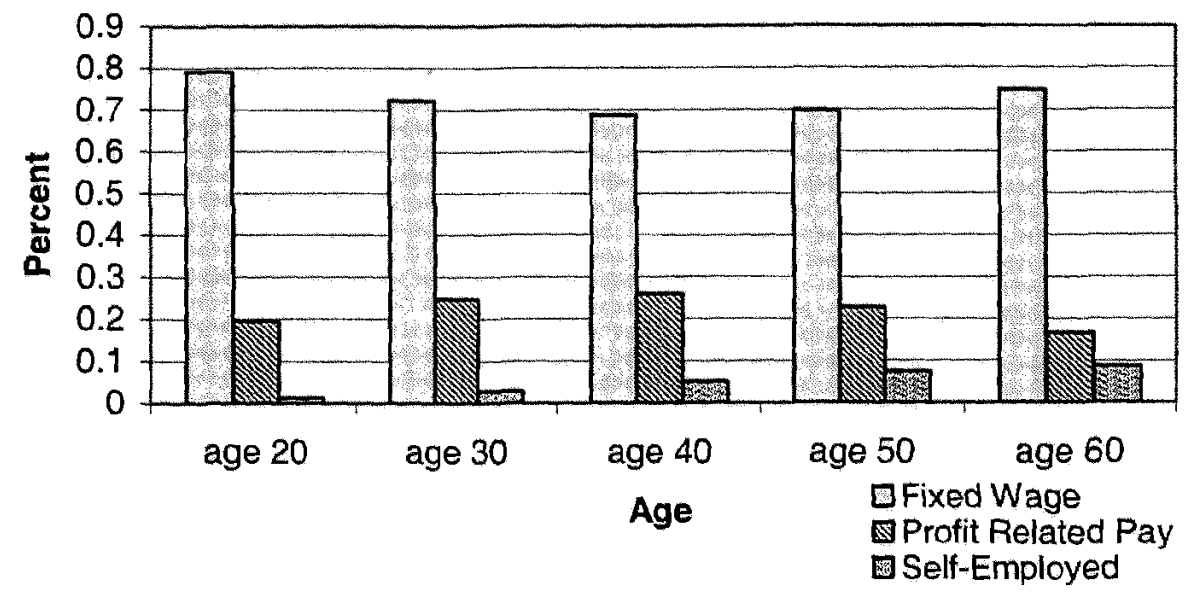

With respect to gender, the results suggest that, compared to workers employed on fixed wage contracts and on PRP, self-employed workers are less likely to be female. PRP workers have 
fewer children of school age whereas self-employed workers are more likely to have both more preschool and school-age children, relative to fixed wage workers.

There is some evidence that higher levels of human capital as proxied by education are associated with PRP. In contrast to other authors (for example, Rees and Shah, 1986, Borjas, 1986, Borjas and Bronars, 1989 and Evans and Leighton, 1989), we find no evidence that educational attainment is positively correlated with the probability of self-employment. The predicted probabilities by educational attainment for the different types of employment contract are shown in Figure 4.

Figure 4: Predicted Probabilties- Education

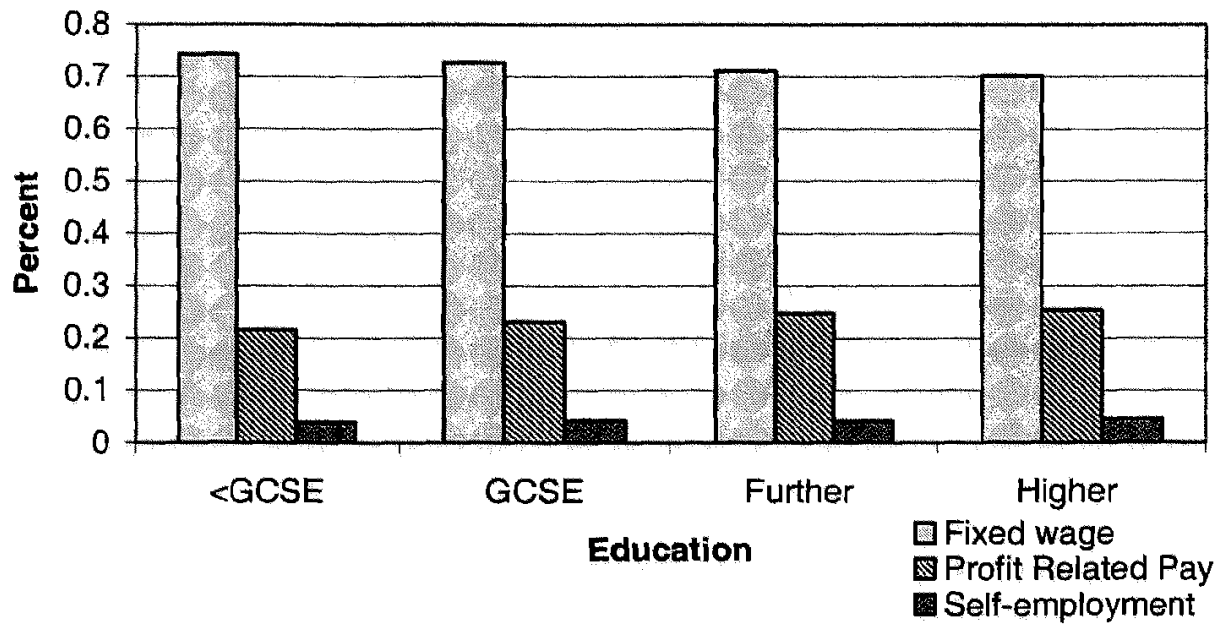

Regarding housing tenure, it would appear that, relative to fixed wage employees, PRP workers are relatively more likely to be living in mortgaged homes ceteris paribus. In terms of occupational status, it is apparent that, relative to fixed wage employees, PRP employees and the self-employed are more likely to be in the professional occupational category.

Finally, turning to our risk preference proxies we observe that, compared to fixed wage employees, PRP workers and the self-employed spend relatively less on financial security ceteris paribus. That is, the degree of investment in financial security is inversely related to the degree of income risk associated with an individual's employment contract. With respect to consumption risk we can see that there is a positive relationship with the degree of income risk (significant at the 
$10 \%$ level). These results suggest the existence of some form of systematic relationship between risk preferences (proxied by our two factors) and employment within a particular type of contract. These findings are consistent with the hypothesis that there is a positive association between income risk and an individual's level of risk preference. The higher the individuals' preference for risk (in terms of lower levels of financial security and higher levels of consumption of risky products) the greater the probability that the individual will hold a contract type characterised by high levels of income risk. These findings are consistent with the studies cited earlier regarding risk preference and self-employment but are derived from a much richer data set that accounts for income risk ordered across three types of employment contract; fixed wage workers, PRP and selfemployment.

\section{Final Comments}

In this paper we have investigated the implied degree of 'risk' associated with self-employment, PRP and fixed wage employment. Our focus is the implied degree of income risk associated with each type of employment contract. We therefore regard fixed wage employment as the most stable and, conversely, self-employment as the most risky (previous caveats noted). We regard PRP contracts, comprising an element of both fixed and variable pay, as being a middle road between the two extremes.

We have investigated the relationship between employment within a particular contract type and risk preference, as proxied through principal component factor analysis whereby a host of expenditures on risky goods and goods associated with risk aversion have been reduced to two factors. The first factor representing 'financial security' and the second factor representing 'risk' Our results allude to a systematic relationship between our risk preference proxies and employment within a particular type of contract. Indeed, risk preferring behaviour is found to be positively correlated with income risk. Moreover, we have shown the presence of an ordering across employment contracts consistent with the level of income risk associated with contract types. 
Our findings contribute to the current debate focusing on the relationship between risk loving behaviour and entrepreneurial success - see, for example, Van Praag and Cramer (2001). Van Praag and Cramer (2001) find that risk aversion is a serious impediment to entrepreneurship in that a successful entrepreneur should be willing to bear risk. In the context of their paper, the size of the work force employed is taken as a measure of entrepreneurial success. Our findings suggest that a link between risk preferring behaviour and type of employment contract exists. To be specific, our findings indicate that the self-employed are likely to exhibit risk loving behaviour which, according to the findings of Van Praag and Cramer (2001), suggests that these individuals are more likely to be successful entrepreneurs relative to individuals with different risk preferences. Furthermore our results suggest that risk averse individuals are more likely to be fixed wage employees rather than unsuccessful entrepreneurs. The existence of PRP provides an alternative for those individuals with some taste for risk, but who are not sufficiently risk loving to enter selfemployment. From society's point of view, such findings may reflect an optimal matching of employment contract type and risk preference in that self-employment is often regarded as the sector of the economy that stimulates the demand for labour and promotes job creation thereby helping to alleviate unemployment and poverty. 


\section{References}

Barsky, R. B., F. T. Juster, M. S. Kimball, and M. D. Shapiro. (1997). 'Preference Parameters and Behavioural Heterogeneity: An Experimental Approach in the Health and Retirement Study.' Quarterly Joumal of Economics, pp. 537-579.

Blanchflower, D. G. and A. J. Oswald (1998). 'What Makes an Entrepreneur?' Joumal of Labor Economics, 16(1), pp. 26-60.

Blinder, A. (ed.). (1990). Paying for Productivity: A Look at the Evidence. Washington, D.C.: The Brookings Institution.

Borjas, G. I. (1986). 'The Self-employment Experience of Immigrants.' The Journal of Human Resources, Volume 21, pp. 485-506.

Borjas, G. I. and S. G. Bronars (1989). 'Consumer Discrimination and Self-employment.' Journal of Political Economy, Volume 97, pp. 581-605.

Borooah, V. K. and M. Hart (1999). 'Factors Affecting Self-Employment among Indian and Black Caribbean Men in Britain.' Small Business Economics, 13(2), pp. 111-129.

Brockhaus, R. and P. Horwitz (1986). 'The Psychology of the Entrepreneur.' in The Art and Science of Entrepreneurship, edited by D. Sexton and R. Smilor, Cambridge, Mass.: Ballinger.

Brockhaus, R. H. (1980). 'Risk-Taking propensity of Entrepreneurs.' Academy of Management Journal, 23, pp. 509-520.

Brown, S., Farrell, L. and J,G, Sessions (2001). 'Employment Contract Matching: An Analysis of Dual Earner Couples and Working Households' University of Leicester, Department of Economics, Working Paper, 01/9.

Calvo, G. and S. Wellisz. (1980). 'Technology, Entrepreneurs and Firm Size.' Quarterly Journal of Economics, 85, pp. 663-678.

Clark, K. and S. Drinkwater (2000). 'Pushed Out or Pulled In? Self-Employment among Ethnic Minorities in England and Wales.' Labour Economics, September 2000, pp. 603-28.

Evans, D. S. and B. Jovannvic. (1989). 'An Estimated Model of Entrepreneurial Choice under Liquidity Constraints.' Journal of Political Economy, 97, pp. 808-827.

Evans, D. S. and L. S. Leighton. (1989). 'Some Empirical Aspects of Entrepreneurship.' American Economic Review, Volume 79, pp. 519-535.

Fry, T.R.L, Brooks, R.D., Comley, B.R. and J. Zhang (1993), 'Economic Motivations for Limited Dependent and Qualitative Variable Models.' Economic Record, 69, pp. 193 - 205. 
Fry, T.R.L. and Harris, M.N. (1996). 'A Monte Carlo Study of Tests for the Independence of Irrelevant Alternatives.' Transportation Research Series B, 28B, pp. 19-30.

Gaynor, M. and P. Gertler. (1995). 'Moral Hazard and Risk Spreading in Partnerships.' RAND Joumal of Economics, 26(4), pp. 591-613.

Georgellis, Y. and H. J. Wall. (2000). 'Who Are the Self-Employed?' Federal Reserve Bank of Saint Louis Review, 82(6), pp. 15-23.

Hersch, J. and T. S. Pickton. (1995). 'Risk-Taking Activities and Heterogeneity of Job-Risk Tradeoffs.' Joumal of Risk and Uncertainty, 11, pp. 205-217.

Hersch, J. and W. K. Viscusi. (1990). Cigarette Smoking, Seatbelt Use, and Difference in WageRisk Tradeoffs, Journal of Human Resources, 25(2), pp. 202-227.

Holtz-Eakin, D., D. Joulfaian and H. S. Rosen. (1994a). 'Entrepreneurial Decision and Liquidity Constraints.' Rand Journal of Economics, 25, pp. 334-347.

Holtz-Eakin, D., D. Joulfaian and H. S. Rosen. (1994b). 'Sticking it Out: Entrepreneurial Survival and Liquidity Constraints.' Journal of Political Economy, 102, pp. 53-75.

Jovanovic, B. (1994). 'Firm Formation with Heterogeneous Management and Labour Skills.' Small Business Economics, 6, pp. 185-191.

Kalldor, N. (1934). 'The Equilibrium of the Firm.' Economic Journal, 44, pp. 60-76.

Kanbur, S. M. (1979). 'Of Risk Taking and the Personal Distribution of Income.' Journal of Political Economy, 87, pp. 760-797.

Keeble, D., S. Walker, and M. Robson. (1993). 'New Firm Formation and Small Business Growth in the United Kingdom.' Employment Department Research Series No. 15, University of Cambridge.

Kihlstrom, R. E. and J. J. Laffont. (1979). 'A General Equilibrium Entrepreneurial Theory of New Firm Formation Based on Risk Aversion.' Journal of Political Economy, 87, 304-316.

Knight, F, H. (1921). Risk, Uncertainty and Profit, New York: Houghton Mifflin.

Le, A-T. (1999). 'Empirical Studies of Self-Employment.' Journal of Economic Surveys, 13(4), pp. $381-416$.

Lucas, R. E. (1978). 'On the Size Distribution of Business Firms.' Bell Journal of Economics, 9, pp. 508-523.

Maddala, G.S. (1989), Limited Dependent and Qualitative Variables in Econometrics, Cambridge University Press, Cambridge.

Parker, S. C. (1996). 'The Effects of Risk on Self-Employment.' Small Business Economics, 9, pp. $515-522$. 
Rees, H. and A. Shah. (1986). 'An Empirical Analysis of Self-employment in the UK.' Journal of Applied Econometrics, 1, pp. 95-108.

Robson, A. J. (1996). 'The Evolution of Attitudes to Risk: Lottery Tickets and Relative Wealth.' Games and Economic Behaviour, 14, pp. 190-207.

Seiler, E. (1984). 'Piece Rates vs. Times Rates: The Effect of Incentives on Earnings.' The Review of Economics and Statistics, LXVI (3), pp. 363-376.

Shapiro, C. and J. E. Stiglitz. (1984). 'Equilibrium Unemployment as a Worker Discipline Device.' American Economic Review, 74, pp. 433-44.

Shaw, K. L. (1996). 'An Empirical Analysis of Risk Aversion and Income Growth.' Journal of Labor Economics, 14(4), pp. 626-653.

Small, K. (1987). 'A Discrete Choice Model for Ordered Alternatives.' Econometrica, 55, pp. 409424.

Small, K. (1994). 'Approximate Generalised Extreme Value Models of Discrete Choice.' Journal of Econometrics, 62, pp. 351-382.

Spearman, C. (1904) 'General Intelligence Objectively Determined and Measured.' American Journal of Psychology, 10, pp. 201-293.

Taylor, M. P. (1996). 'Earnings, Independence or Unemployment: Why Become Self-Employed?' Oxford Bulletin of Economics and Statistics, 30, pp. 194-204.

Van Praag, C. M. and J. S. Cramer. (2001). 'The Roots of Entreprenearship and Labour Demand: Individual Ability and Low Risk Aversion.' Economica, 2001, pp. 45-62.

Weitzman, M. (1985). 'The Simple Macroeconomics of Profit-Sharing.' American Economic Review, 75, pp. 937-953.

Wortman, M. (1987). 'Entrepreneurship: An Integrating Typology and Evaluation of the Empirical Research in the Field.' Joumal of Management, 13(2), pp. 259-279. 
RESEARCH PAPER SERIES - RECENT PUBLICATIONS IN THE DEPARTMENT OF ECONOMICS

NO. AUTHOR/S

TITLE

DATE

INTERNAT. ISBN NO.

TOTAL

WORKING

NO. OF

PAPER NO.

PAGES

839 Martin S. Chin

840 Suren Basov

841 Akihito Asano

842 Robert Dixon, John Freebairn \&

G. C. Lim

843 Suren Basov

844 Martin J. Osborne \& Rabee Tourky

845 Sarah Brown, Lisa Farrell, Mark

N. Harris \& John

G. Sessions
Modelling Social Infrastructure and Growth

Why Do Social Skills Matter?

Inequality and Growth: Non-Monotonic Effects via Education and Fertility

Why are Recessions as deep as they are? The Behaviour Over Time of the Outflow from Unemployment: A New Perspective

Imitation and Social Learning

Party Formation in Collective Decision-Making

Risk Preference and Employment Contract Type
March 2002

March 2002

March 2002

April 2002

April 2002

April 2002

April 2002
IWP 776

IWP 777

IWP 778

$0734024940 \quad 32$

$0734024959 \quad 19$

073402496735

IWP 779

$0734024975 \quad 40$

IWP 780

073402498323

IWP 781

073402499133

IWP 782

073402500931 